\title{
A Need to Protect What is Already Existent: Alcohol Community Detoxifications in Primary Care: Primary Care Services Islington Whittington NHS Trust
}

\author{
Jeff Fernandez* \\ Lead Nurse for Primary Care Islington, Camden and Islington Mental Health Trust, London
}

*Corresponding author: Jeff Fernandez, Lead Nurse for Primary Care Islington,

Better Lives, Camden and Islington Mental Health Trust, London.

Received Date: November 05, 2018

Published Date: November 20, 2018

\begin{abstract}
This paper is outlining the valuable work that has been completed in primary care for patients who have dependent patterns around alcohol use. Due to the economic climate of austerity alcohol and drug services have had to endure large financial cuts and this has led to some service provision being dis-continued or at best streamlined. This paper asks that nurse-led detoxifications are important for patients to access in primary care. If there is streamlining it needs to be conducted where the best parts of a service are kept. Alcohol detoxifications in primary care are such a service.Conclusion: There are personal and organizational factors that are influencing the nurse's work motivation in Jeddah, which should be met and considered by nursing management.
\end{abstract}

\section{Introduction}

In line with the recovery agenda, all drug and alcohol funding nationally has experienced some form of financial cut as a result from being moved from the NHS to the public health budget held by local authorities. This has challenged commissioners for budget savings as local authority funding is all squeezed. In this now streamlined drug and alcohol service, often primary care drug and alcohol treatment has been severely reduced, and side lined with the loss of very effective care. This paper argues that services such as nurse-led alcohol detoxifications completed in primary care in Islington (London) can be lost and this has been a very effective recovery pathway for patients. Areas such as this are important to protect especially in the 'Recovery' led approach to drug and alcohol provision.

Community detoxification is usually asked for by patients who present to alcohol as the first line and preferred mode of treatment. This is seen as an effective treatment pathway for many patients that present to primary care and can be enabling for them to experience some 'dry' time from alcohol [1]. There is some evidence to suggest that this can be as effective as in-patient detoxification off alcohol and cheaper to complete [2].

Therefore, this paper is looking at the planned detoxifications that were completed in the community for over two years in 2016
$\& 2017$. All of the detoxes were completed in primary care by the specialist primary care alcohol team based in Islington London. It examines the cohort that within the data collected within a 24-month period. It highlights the important nurses can do in primary care and how this valuable work should be priority in these 'Auster' times. It illustrates this through a typical case study.

Primary care alcohol and drug service (Pcads): Islington shared care

This service was established in 2007 as an alcohol and drug service for patients who are registered at Islington G. P's. The service provided a framework for the development of PCADS detoxification protocol that was produced to inform the team of a safe and effective way to complete community detoxifications. The service provides in-reach to all GP surgeries in Islington currently at 34 practices. It does this by providing nurses' that can also provide Non-medical prescribing and therefore assess, manage and prescribe for the patients holistically. Therefore, in essence, the patient presenting for alcohol treatment need only see one clinician for every aspect of care (alcohol) and this provides a quick accessible service for patients. Community detoxification is a large part of the activity of the shared care team and is defined as: A prescribed clinical detoxification process which is given in the 
community with a level of patient monitoring which is less than in the in-patient setting. It is given to patients who are assessed as 'at low risk of complications' with a daily regimen instructed by the clinician to enable the patient to manage their detoxification regime.

\section{Data Collection}

\section{Data collection (1)}

Data on the community detoxification was taken from the last two years of PCADS activity that spanned from the time frame of April 2015 to April 2017. In this time period there were 98 community detoxes completed for the service and some of the patients in this data had more than one community detoxification.

From the 98, this ratio the drop out is also very small, however, this will be the focus of another paper, for as mentioned a typical patient that have more than one detox will be examined in detail through a case study analysis.

At present how the service operates is, there are two main ways patients are detoxed in PCADS. One is ambulatory that is a hospital-based detoxification of alcohol conducted through the outpatient department. This is for patients that are admitted into hospital and are discharged earlier if they are able be seen every day in an outpatient department. This is a process that works for patients reluctant to stay in hospital and can be very cost effective. In Islington a bed night saved by this service can save up to 200 pounds a night.

The community detoxes are conducted out of general practices in Islington. As described before, the patients need to meet the criteria. This usually excludes very dependent drinkers who are physical very unwell. The detoxifications are usually planned and there is some preparation time as well. In this time, the patient is asked to outline their alcohol pattern and focus on the triggers for alcohol. This will hopefully try to increase understanding and insight into their alcohol pattern. Then the detoxification will be planned when there has been a reduction in their alcohol consumption from the original figure given at the assessment stage. Therefore, the detoxifications being planned, can give the team valuable time to work with a patient to be ready for a detoxification and focus on the period after this to establish potential some dry time.

\section{Data collection (2)}

Data on the community detoxification was taken from the last two years of PCADS activity that spanned from the time frame of April 2015 to April 2017. In this time period there were 98 community detoxes completed for the service and some of the patients in this data had more than one community detoxification. This cohort when examined is a small part of the overall figure that may indicate that maybe the preparation work of the majority of patients is good and they achieve 'dry' time in order not to re-visit the service again for another community detoxification. Or they relapse and indeed drop out of treatment. From the 98, this ratio that drop out is also very small, however, this will be the focus of another paper, for as mentioned the patients that have more than one detox will now be examined. First here are some summary charts that indicate some the data analysed from the two years activity of the PCADS in Islington.

The above chart illustrates how the service operates and there are two main ways patients are detoxed in PCADS. One is ambulatory that is a hospital-based detoxification of alcohol conducted through the outpatient department. This is for patients that are admitted into hospital and are discharged earlier if they can be seen every day in an outpatient department. This is a process that works for patients reluctant to stay in hospital and can be very cost effective. In Islington a bed night saved by this service can save up to 200 pounds a night.

The community detoxes are conducted out of general practices in Islington. As described before, the patients need to meet the criteria. This usually excludes very dependent drinkers who are physical very unwell. The detoxifications are usually planned and there is some preparation time as well. In this time, the patient is asked to outline their alcohol pattern and focus on the triggers for alcohol. This will hopefully try to increase understanding and insight into their alcohol pattern. Then the detoxification will be planned when there has been a reduction in their alcohol consumption from the original figure given at the assessment stage.

Therefore, the detoxifications being planned, can give the team valuable time to work with a patient to be ready for a detoxification and focus on the period after this to establish some dry time. This figure looks at the gender mix of the patients that present for a community detoxification in primary care Islington. This has always been at the same level for many years. It is roughly a twothirds male to a third females' split. This would indicate what is a national picture in that males are better represented in services than females. Particularly in drug and alcohol services where the gender split nationally is a 4:1 ratio in favour of males [3].

This is also similar to previous statistics. However, PCADS is seeing an aging population that is indicated in the above chart for the number of community detoxifications over a two-year period. The number of detoxes for the patients over the age of 45 at $67 \%$ of the all the detoxes completed. This is a significant figure. It does indicate that the older the patients the more likely they have been exposed to alcohol treatment in the past and therefore would enable them to make better use of services when needed to achieve their aims for treatment. However, this will also be the subject of another paper as mentioned the scope of this paper is to focus on the patients that have had more than one detoxification and the significance of this chart is that this cohort of patients, in the majority are also over 45 and have been exposed to treatment before.

\section{More than one community detoxification}

This section will examine the cohort that have had more than one detoxification over the time period of a year from April 20162017. This cohort when examined is a small number of patients at twelve exactly. The number of detoxifications that have been completed by this cohort are now shown below.

As one can see the majority of patients need only two to three community detoxes however there is a few patients that have 
needed more than this. The question this paper will ask is there any 'dry' time achieved in between each detoxification and how does this relate to the next detox. Does it inform the patients to be better able to achieve their aim of abstinence off alcohol? Or does it take for some patients more than a few detoxifications of alcohol to achieve some 'real' abstinence off alcohol therefore giving a rationale of giving a patient more than five or even six opportunities to access alcohol detoxifications (Figure 1-3).
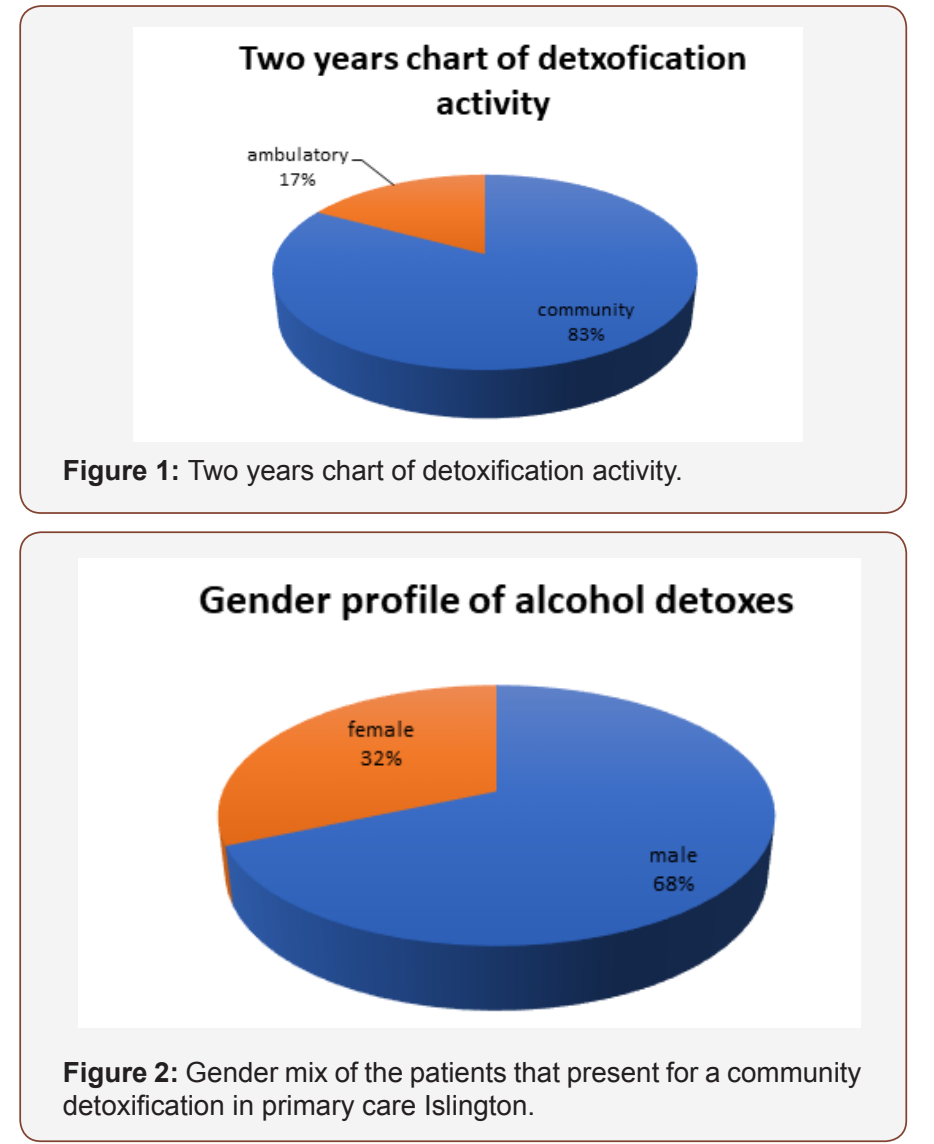

\section{Age profile of community detoxes completed by PCADS}

=age $25-34=$ age $35-44=45-50=50-55=55-60=60+$

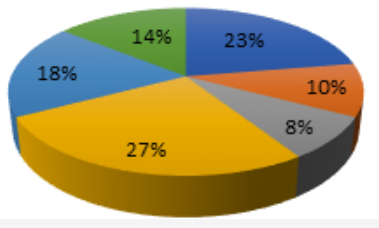

Figure 3: Nurses' level of happiness as presented by percentages.

The chart above shows the age profile of the patients that need more than one detoxification. The majority are overwhelming over 40 years plus with 8 being over 45 years of age. This does show similar findings to the first chart that the patients that do detox that tend to be older are more experienced in alcohol treatment and therefore are more able to understand what services can be provided. Also, they are able to use them to meet their aims as well. Since the cohort is small there is an opportunity for it to be studied in more details and the case study analysis would indicate the best approach to this. This is now explained and its applicability.

\section{Case Studies}

Case studies used here are looking at the individual cases that do engage with community services in Islington, as these patients can show the service of what works so that this process can be more uniform. Case studies in this sense can be informative and enlightening. They can be very useful for medical research and provide clinical staff with very good information from an in-depth study that can improve care [4]. This is the purpose of this paper to see if the valuable things that help people engage and can this be worked into a uniform process [4-17].

Since the number are small there is an opportunity to use the case study approach to look in-depth to the profile of the patients and see if there are any major factors or commonality that can be informative to clinical staff. It could improve and inform the community detoxification process for PCADS and also, a wider audience of clinical staff that conduct community detoxification for alcohol dependent patients. The patient with more than one detoxification from alcohol will now be examined as a typical patient that needed more than one detoxification (Figure 4-5).

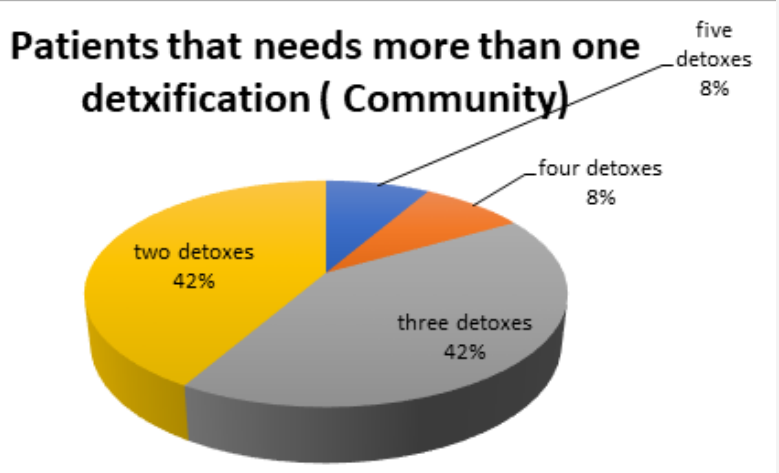

Figure 4: Nurses' level of happiness as presented by percentages.

\section{Age profile of patients with detoxifcation >} 1

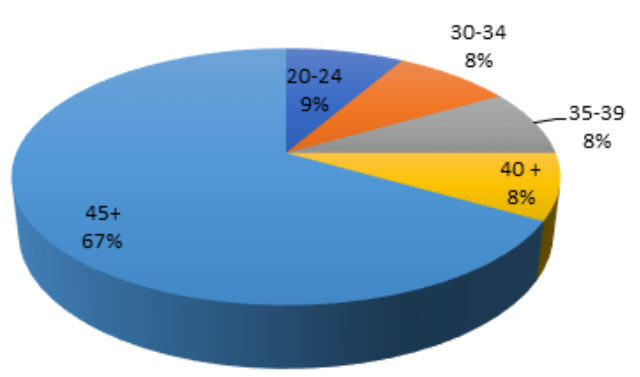

Figure 5: Nurses' level of happiness as presented by percentages.

\section{Case study: patient $A$}

This case study is a patient that does have a high degree of typicality for the patients that present to primary care. Patient 
A was a female and was 44 years old. She had twenty years of dependent alcohol drinking and used no other illicit drug at all. She has some liver damage and was told by her GP that if she continued to drink alcohol, she would be vulnerable to liver damage which could irreversible. She had previously been to the specialist service but found this too impersonal and they had drinkers she knew attending there. She went there once and after her assessment met a friend there and they started drinking heavily after. She wanted a more personal service with one-to-one sessions that could be provided in primary care. She also wanted something that was very close to her home as well. She booked an appointment to see a nurse at the surgery and was seen in one week.

She had been seen before but always dis-engaged after a few sessions as she reduced her drinking and thought she was OK and did not need any further help. However, this presentation was different as she had been told that he is drinking was affecting her health. She said' she got a shock' and wanted now to really try and change her pattern of drinking. She had never considered a community detoxification before, as the thought of not having any alcohol was something she had ever thought about. However, she wanted to try this now as she now saw the benefit of some time off alcohol. She was suitable for an alcohol detoxification as she had not suffered from alcohol withdrawal fits and could reduce her alcohol whilst she was in treatment. She did not have good insight into being 'dry' as she had never achieved this in twenty years. We discussed the use of aftercare medications and thought that disulfiram would be a good medication for her to try after the detoxification to help her go 'dry' (Off alcohol) for longer. She reduced her alcohol intake from 200 units a week to 100 units a week in four weeks. She was developing some insight into how difficult it would be for her to achieve alcohol free time, but she wanted to try. She attended AA groups which she found very helpful in increasing her insight by listening to other people's stories of how they stopped. This was valuable for her to hear as this did increase her ability to envisage what she would need to do to stay 'dry'.

She started her detoxification and within five days she had completed this regime successfully. She started on disulfiram and she found this really useful as previously, she did drink on top of this medication and experienced the side effects of severe sickness and was determined not to repeat this again.

This regime was beneficial for her for six months and her liver results did show signs of improvement, however she was not able to sustain her 'dry' period and relapsed after six months. However, for a patient that had no period in the last twenty years without alcohol this was a very good achievement and proved to her she could go alcohol free. (Important for her as she wanted to re-visit this treatment again). We worked on her insight and she was better and more honest and therefore better able to understand her pattern around alcohol. After three months she detoxed again, and she has now been 'dry' (At the moment of writing this) for a year to date. She has no desire to return to alcohol and her liver results are very much improved. She is still attending AA meetings as well and finds these very valuable as it reminds her of how damaging alcohol can be.
Also valuable was the service in primary care being able to accommodate one-to-one sessions and also be very close to home. It was not a big service where she would meet other dependent drinkers, and this was very valuable for her staying 'dry' she stated.

\section{Conclusion}

Therefore, the delivering of community alcohol detoxifications in primary care can enable patients a chance of living an alcoholfree life. This is a very valuable service delivered in premises close to the patient that makes engaging the patient more likely. This can also avoid a costly in-patient detoxification as well.

This paper does show the work completed by the shared care team in Islington and the value this can have for individuals. In the light of the economic climate of austerity and limited budgets for the NHS, services like this need to be promoted and argued as protected. Effective and efficient services need not be streamlined or changed but promoted showing the value good NHS primary care have on the general population.

\section{Acknowledgement}

None.

\section{Conflict of Interest}

\section{No Conflict of Interest.}

\section{References}

1. Fernandez J (2016) Alcohol Community Detoxification Guidelines. Whittington Health NHS Local Paper.

2. Raistrick D, heather N, godfrey C (2006) review of the effectiveness of treatment for alcohol problems. National Treatment agenency for substance misuse.

3. NTA (2017) Drug Misuse and dependence-UK guidelines on clinical management.

4. McNiff J (2014) Writing and Doing Action Research. Sage Publications London,

5. Agency for Substance Misuse. London: Department of Health. Ritchie J \& Lewis J (eds.) (2003). Qualitative Research Practice, A Guide for Social Science Students and Researchers, London.

6. Croxford A, Notley JC, Maskrey V, Holland R, Kouimtsidis C (2015) An exploratory qualitative study seeking participant views evaluating group Cognitive Behavioral Therapy preparation for alcohol detoxification. Journal of Substance Use 20(1): 61-68

7. Drummon C, Oyefeso A, Phillips T, Cheeta S, Deluca P, et al. (2005) Alcohol Needs Assessment Research Project (ANARP); The 2004 National Alcohol needs Assessment for England. Department of Health, London, England.

8. Fernandez J (2013) Introducing the Role of Recovery into Patients' pathways. National Association of Primary Care Review.

9. Gossop M (2015) The National Treatment Outcomes Research Study (NTORS) and the influence on addiction treatment policy in the United Kingdon NTORS and treatment policy.

10. Green J \& Thorogood N (2004) Qualitative Methods for Health Research, Sage Publications, London, England.

11. Kouimtsidis C, Ford L (2010) A staged programme approach for alcohol dependence: Cognitive Behaviour Therapy groups for detoxi- fication preparation and aftercare; preliminary findings. Short report. Drugs: Education, Prevention and Policy 19: 81-83.

12. Kouimtsidis C, Drabble K, Ford L (2012) Implementation and evaluation of a three stages community treatment programme for alcohol 
dependence. A short report. Drugs: Education, Prevention and Policy 19: 81-83.

13. Kouimtsidis C, Kolli S (2013) Preparation for alcohol detoxification group programme. Service users' evaluation of individual sessions. Journal of Substance Use 19: 184-187.

14. McNiff J (2014) Writing and Doing Action Research. Sage Publications London,

15. Monti PM, Abrams DB, Kadden RM, Cooney NL (1989) Treating Alcohol Dependence: A Coping Skills Training Guide. Guilford Press, London.
16. National Institute for Health and Clinical Excellence (2011) Alcohol use disorders: Guidelines on diagnosis, assessment and management of harmful drinking and alcohol dependence. The British Psychological Society and The Royal College of Psychiatrists. Leicester (UK): British Psychological Society.

17. Public Health England (2016) The Public Health Burden of Alcohol and the Effectiveness and Cost-effectiveness of Alcohol Control Policies. 